\title{
Papillary fibroelastoma in the left atrium
}

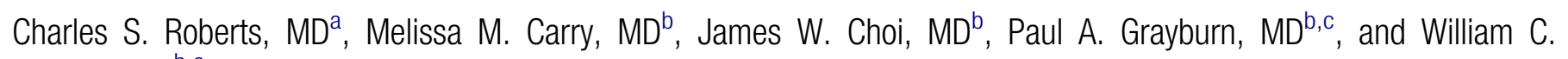
Roberts, $M D^{\mathrm{b}, \mathrm{C}}$

${ }^{a}$ Department of Cardiac Surgery, Baylor University Medical Center, Dallas, Texas; ${ }^{b}$ Division of Cardiology, Department of Internal Medicine, Baylor University Medical Center, Dallas, Texas; 'Baylor Scott \& White Heart and Vascular Institute, Baylor University Medical Center, Dallas, Texas

\section{ABSTRACT}

Described herein is a 71-year-old woman with previous angina pectoris who suddenly developed slurred speech and right-arm weakness. She was found to have significant coronary narrowing, a small mass in the left atrium attached to the endocardium near the orifice of the appendage, and multifocal punctate cerebral lesions in the distribution of the left middle cerebral artery. The left atrial mass was excised and confirmed to be a papillary fibroelastoma. Coronary bypass was also performed. It is believed that fibrin thrombus developed within the fronds of the fibroelastoma and embolized to the brain. Such lesions in the left atrium are exceedingly uncommon. She had no further emboli events.

KEYWORDS Angina pectoris; papillary fibroelastoma

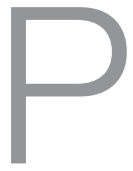

apillary fibroelastomas are commonly seen in the heart. ${ }^{1}$ Most often they involve one or both leftsided cardiac valves, occasionally the tricuspid valve, and less frequently the mural endocardium of the left ventricle. Their occurrence on the left atrial mural endocardium is exceedingly rare. Such was the case, however, in the patient described herein.

\section{CASE DESCRIPTION}

A 71-year-old white woman, who was born in February 1947, was healthy until age 66 (February 2014) when she suddenly developed substernal chest pain that radiated to her left arm and prompted cardiac catheterization that disclosed narrowing (diameter reduction) of the coronary arteries as follows: left main 10\%; left anterior descending 40\%; left circumflex 10\%; and right (proximally) 99\%. A drug-eluting stent was inserted into the right coronary artery with relief of the stenosis. At the time, the left ventricular function was normal, and the four cardiac chambers were of normal size. Her total cholesterol was $130 \mathrm{mg} / \mathrm{dL}$ and low-density lipoprotein cholesterol was $47 \mathrm{mg} / \mathrm{dL}$ (on rosuvastatin).
Thereafter, she was well until age 71 (March 2018) when at home she suddenly developed slurred speech and right-arm weakness. By the time she arrived at the hospital within an hour, both speech and weakness had improved. Magnetic resonance imaging disclosed multifocal punctate acute infarcts in the cerebrum in the distribution of the left middle cerebral artery with a pattern suggestive of embolism. The electrocardiogram and troponin I level were normal. Her body mass index was $32 \mathrm{~kg} / \mathrm{m}^{2}$. Echocardiogram disclosed a small mass attached to the mural endocardium near the ostium of the left atrial appendage (Figure 1). Erythrocyte sedimentation rate was $78 \mathrm{~mm} / \mathrm{h}$, hematocrit $38 \%$, and C-reactive protein $14.3 \mathrm{mg} / \mathrm{dL}$. Repeat coronary angiogram showed the following degrees of narrowing (diameter reduction): left main $10 \%$; left anterior descending $70 \%$; left circumflex $10 \%$; left obtuse marginal $80 \%$; and right $10 \%$. The left ventricular size and wall motion were normal. The ejection fraction was $60 \%$.

In June 2018 , the left atrial mass $(1.2 \times 0.7 \mathrm{~cm})$ was excised (Figure 2), along with the underlying endocardium to which it was attached. A left internal mammary artery was anastomosed to the left anterior descending, and a saphenous venous conduit was anastomosed to the first obtuse marginal

Corresponding author: Charles S. Roberts, MD, Department of Cardiac and Thoracic Surgery, Baylor University Medical Center, 3900 Junius, Suite 415, Dallas, TX 75246 (e-mail: Charles.Roberts@BSWHealth.org)

Color versions of one or more of the figures in the article can be found online at www.tandfonline.com/ubmc.

Received November 15, 2018; Accepted November 19, 2018. 

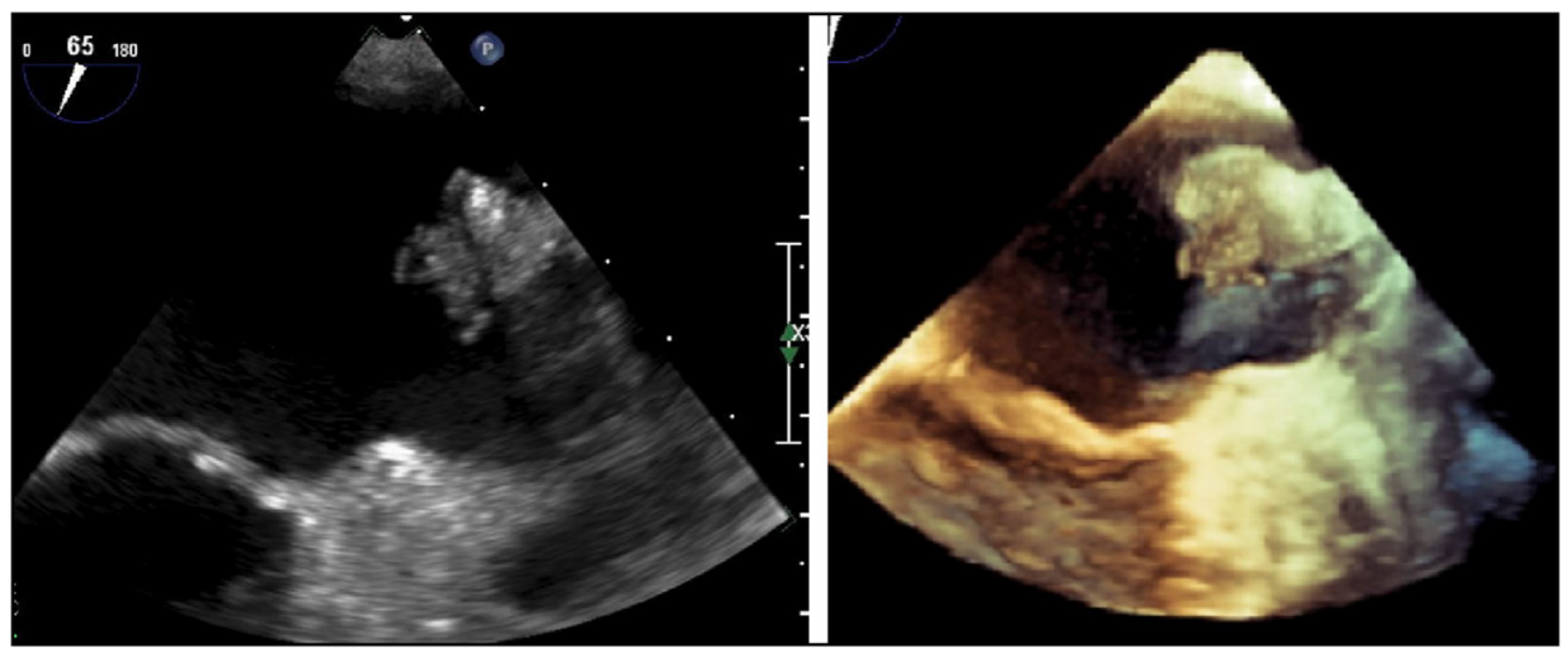

Figure 1. Echocardiogram.

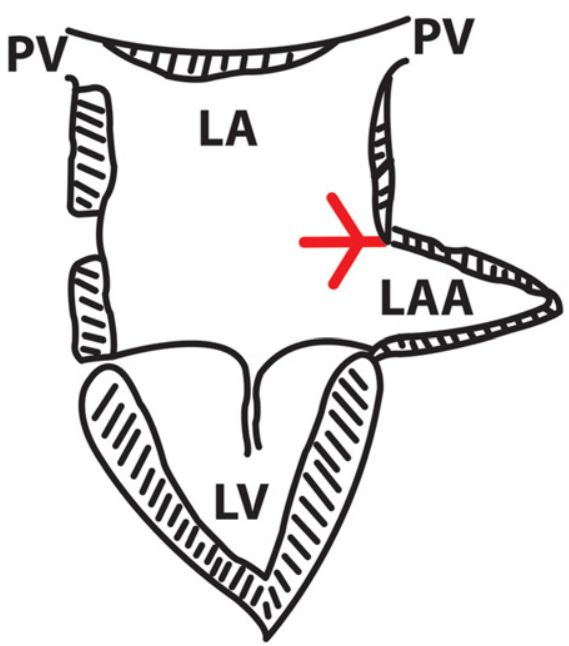

Figure 2. Diagram showing the location of the left atrial fibroelastoma.

coronary artery. The left atrial mass was a typical papillary fibroelastoma (Figure 3). In October 2018 (4 months postoperative), the patient was asymptomatic.

\section{DISCUSSION}

Papillary fibroelastoma in the left atrium is rare. Gowda et $\mathrm{al}^{2}$ reviewed 611 previously reported cases of papillary fibroelastoma in which the location of the tumor was described: $84 \%$ were located on one or more valvular cusps and $16 \%$ had a nonvalvular location. Of the latter, $12(2 \%)$ overall were in the left atrial wall. Anastacio et $\mathrm{al}^{3}$ described 23 patients with cardiac papillary fibroma. None occurred in the left atrium. The most common clinical consequence of a

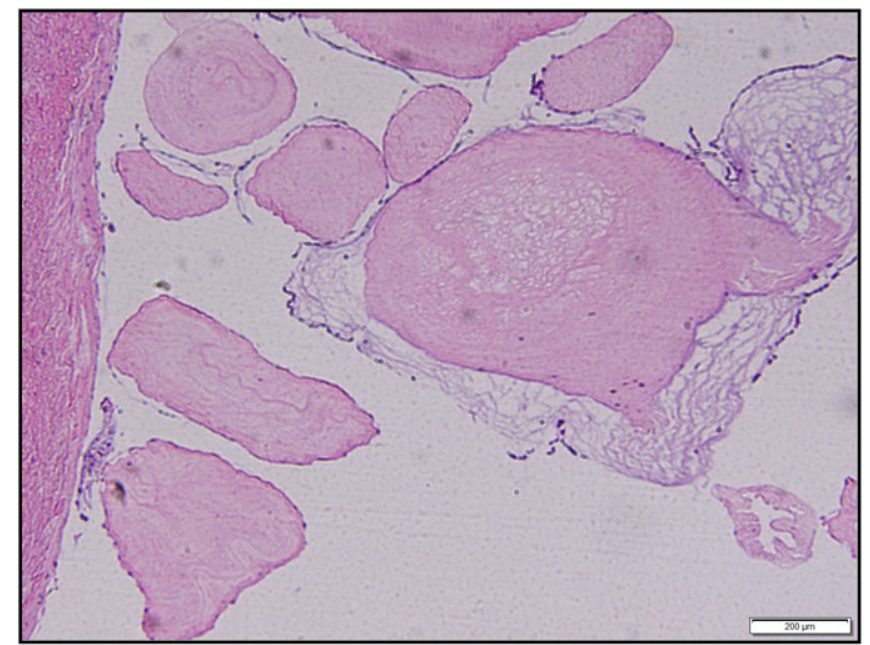

Figure 3. Photomicrograph of the left atrial mass showing the typical fronds. Hematoxylin/eosin stain, $\times 100$.

left-sided papillary fibroelastoma is transient ischemic attack or stroke, as occurred in the patient described who also had concomitant coronary bypass.

1. Roberts WC. Papillary fibroelastomas of the heart. Am J Cardiol. 1997;80(7):973-975.

2. Gowda RM, Khan I, Nair CK, Mehta NJ, Vasavada BC, Sacchi TJ. Cardiac papillary fibroelastoma: a comprehensive analysis of 725 cases. Am Heart J. 2003;146(3):404-410. doi:10.1016/S00028703(03)00249-7.

3. Anastacio MM, Moon MR, Damiano RJ Jr, Pasque MK, Maniar HS, Lawton JS. Surgical experience with cardiac papillary fibroelastoma over a 15-year period. Ann Thorac Surg. 2012;94(2):537-541. doi: 10.1016/j.athoracsur.2012.04.006. 